\title{
Synchronous Volvulus of the Sigmoid Colon and the Transverse Colon: A Case Report at Gabriel Toure University Hospital in Mali
}

\author{
Traoré Amadou1 ${ }^{*}$, Konaté Madiassa', Diarra Abdoulaye ${ }^{2}$, Tounkara Idrissa1, Saye Zakari1, \\ Doumbia Arouna1, Bah Amadou', Sidibé Boubacar Yoro1, Maïga Amadou1, Koné Tani', \\ Thiam Souleymane1, Karembé Boubacar ${ }^{3}$, Kelly Bouréima1, Traoré Kadia ${ }^{3}$, Kéita Koniba², \\ Bouaré Yacouba1, Koné Assitan², Diakité Ibrahim¹, Dembélé Bakary Tientigui1, \\ Traoré Alhassane ${ }^{1}$, Togo Adégné1
}

${ }^{1}$ General Surgery Department, Gabriel Touré University Hospital, Bamako, Mali

${ }^{2}$ Surgery Department, Kati University Hospital, Kati, Mali

${ }^{3}$ Reference Health Center of Commune III, Bamako, Mali

Email: *amadoutra242@gmail.com

How to cite this paper: Amadou, T., Madiassa, K., Abdoulaye, D., Idrissa, T., Zakari, S., Arouna, D., Amadou, B., Yoro, S.B., Amadou, M., Tani, K., Souleymane, T., Boubacar, K., Bouréima, K., Kadia, T., Koniba, K., Yacouba, B., Assitan, K., Ibrahim, D., Tientigui, D.B., Alhassane, T. and Adégné, T. (2021) Synchronous Volvulus of the Sigmoid Colon and the Transverse Colon: A Case Report at Gabriel Toure University Hospital in Mali. Surgical Science, 12 , 313-318.

https://doi.org/10.4236/ss.2021.129032

Received: July 23, 2021

Accepted: September 15, 2021

Published: September 18, 2021

Copyright $\odot 2021$ by author(s) and Scientific Research Publishing Inc. This work is licensed under the Creative Commons Attribution International License (CC BY 4.0).

http://creativecommons.org/licenses/by/4.0/

\begin{abstract}
Synchronous transverse and sigmoid colon volvulus are very rare. We report the case of a 23-year-old man who underwent emergency surgery for sigmoid colon volvulus. An intraoperative finding of transverse colon volvulus associated with sigmoid colon volvulus was made. Left and transverse colectomy was performed followed by colorectal anastomosis. The postoperative period was uneventful. Synchronous volvulus of the transverse and sigmoid colon is a surgical emergency. The clinical signs are not specific and the discovery is often intraoperative. It is necessary to know how to evoke the diagnosis in a case of sigmoid colon volvulus, to avoid inadequate management with dramatic consequences.
\end{abstract}

\section{Keywords}

Volvulus, Synchronous, Colon, Sigmoid, Transverse, Surgery, Mali

\section{Introduction}

Colonic volvulus occurs on mobile segments of the colon and results in intestinal obstruction by strangulation. It is therefore a surgical emergency the consequence of which is the rapid progression to life-threatening intestinal necrosis. The segments usually affected are the sigmoid colon (75\%) and the caecum (22\%); transverse colon volvulus (TCV) is exceptional [1] [2] [3]. The associa- 
tion of TCV with sigmoid colon volvulus (SCV) may be metachronous [4] or synchronous [1] [2] [5]. This association is very rare and discovered intraoperatively in most cases [1] [3] [5] [6]. We report a case of synchronous volvulus of sigmoid colon and transverse colon treated at the Gabriel Touré University Hospital with a review of the literature on diagnostic and therapeutic aspects.

\section{Case Presentation}

A 23-year-old man, single, was admitted in emergency reception department of the Gabriel Touré University Hospital for abdominal pain associated with inability to pass stools and gas.

Symptoms began three days earlier, marked by the sudden onset of pain localized in the hypogastrium, of strong intensity, torsion type, without a triggering factor, radiating into the rest of the abdomen, aggravated by movements, without a calming factor. Pain was associated with inability to pass stools and gas. Vomiting appeared the next day and did not relieve the patient. He had no signs of gastrointestinal bleeding or fever.

Faced with this clinical picture, he unsuccessfully followed traditional treatment and then consulted in a community health center from where he was urgently referred to the Gabriel Touré University Hospital on suspicion of an acute intestinal obstruction.

The patient had a history of chronic constipation. He had no history of surgery.

The general examination on admission found a WHO performance index of 2, arterial pressure at 120/70 $\mathrm{mmHg}$, a pulse at 92 beats/minute, good skin-mucous staining, no dehydration folds but urine dark with a feeling of thirst.

On physical examination, the abdomen was distended and asymmetrical, with painful renitence on palpation, diffuse tympanism form percussion. On rectal examination, the rectal bulb was empty, there was no rectal mass.

A plain abdominal radiography carried out urgently revealed two upside-down $\mathrm{U}$-shaped loops of dilated bowel with air-fluid levels at the feet (Figure 1).

The biological assessment found hemoglobin level at $12 \mathrm{~g} / \mathrm{dL}$, hematocrit at $33.5 \%$, leukocytosis at $9600 / \mathrm{mm}^{3}$.

The diagnosis of SCV was made and the patient underwent an emergency surgery after a short resuscitation.

Under general anesthesia, a median laparotomy was performed. Exploration found a mesenteric-axial SCV with two anti-clockwise turns without necrosis (Figure 2) and a TCV with one anti-clockwise turn without intestinal necrosis (Figure 3). The exploration also found abnormal mobility of the cecum, ascending colon and colonic angles.

After untwisting a left and transverse colectomy followed by manual end-to-end colorectal anastomosis and drainage of the Douglas pouch by a blade of Delbet.

The immediate outcomes were simple; the nasogastric tube was removed the day after the surgery (D1) with a gradual resumption of feeding; transit resumed on D3. The blade of Delbet was removed on D3. The hospitalization duration was 09 days. The late outcomes (at 6 months and 9 months) were simple. 


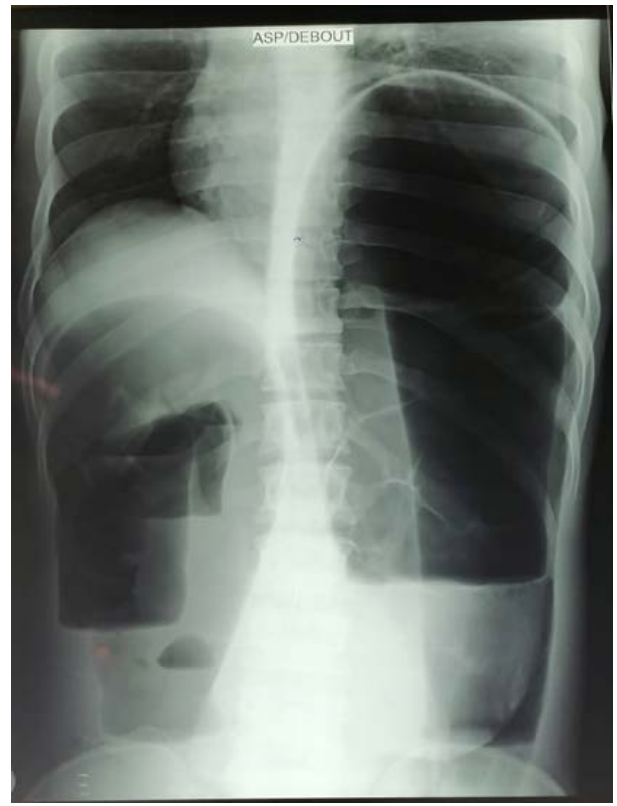

Figure 1. Erect plain abdominal radiography: two upside-down U-shaped loops of dilated bowel with air-fluid levels at the feet.

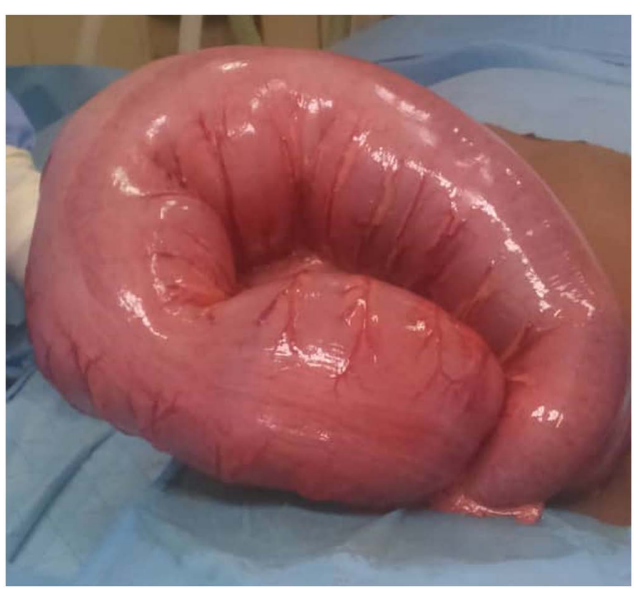

Figure 2. Dilated sigmoid colon without necrosis.

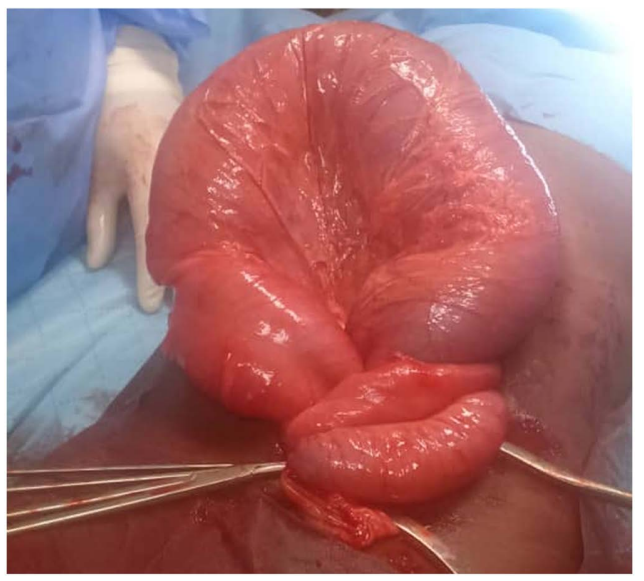

Figure 3. Dilated transverse colon without necrosis. 


\section{Discussion}

Colon volvulus accounts for only $1 \%$ to $7 \%$ of large intestine obstructions in Western Europe and the United States of America [1]. It is common in sub-Saharan Africa where it is the leading cause of colonic obstruction [6]. SCV without necrosis represented $19.06 \%$ of intestinal obstruction operated according to Togo in Mali [7]. Its association with volvulus of another intestinal segment is exceptional. The association of SCV with transverse colon volvulus is very rare; only 7 cases have been reported in the literature in 20 years (between 2000 and 2019) [6].

The most reported contributing factors are abnormal mobility of colonic segments, dolichocolon, narrow mesocolon, chronic constipation [1] [2] [5] [6]. These factors may be congenital in young or acquired patients (especially in elderly patients). Abnormal mobility of the colon was observed in our patient.

The clinical signs have no specificity that could lead to the suspicion of a double colonic volvulus. The clinical picture is that of low intestinal obstruction due to strangulation [3] [5] [6]. Diagnosis may be late at the stage of ischemia or intestinal necrosis in the presence of signs of peritoneal irritation [1] [2].

For most of the cases reported in the literature, morphological examinations performed in emergencies did not allow to suspect the association of the two volvuli, the discovery of which was therefore intraoperative [6]. However, in all the cases reported in the literature, abdominal X-ray or computed tomography (CT) scan revealed massive colonic distension sometimes associated with images in favor of the SCV [1] [2] [5] [6]. In our case, the presence of two upside-down U-shaped loops of dilated bowel with air-fluid levels at the feet on the stereotype of the abdominal X-ray could have given rise to suspicion of the diagnosis. However, these radiological signs can be interpreted as a simple SCV associated with an upstream colonic distension, given the rarity of the possibility of a second associated volvulus. It is therefore essential to make a complete intraoperative colonic exploration so as not to miss a second colonic volvulus associated with the volvulus of the sigmoid colon.

Emergency treatment was surgical in the cases reported in the literature [1] [2] [3] [5] [6] [8] [9]. A total, subtotal or left enlarged colectomy in the transverse colon has been the technique performed in the literature. Immediate restoration of digestive continuity has been preferred by some authors in the absence of intestinal necrosis [2] [3]; others have chosen to perform an emergency first stoma [1] [5] [6]. A case of surgical detorsion followed by cecostomy has been reported [9]. We preferred partial colectomy with immediate colorectal anastomosis (one-step surgery) in the face of favorable local and general conditions (young patient, without comorbidity, absence of intestinal necrosis, correct resuscitation). This choice is justified by a previous study carried out in the service on sigmoid volvulus without necrosis which reported that this method was without additional morbidity and mortality compared to two-stage surgery [7].

In the absence of signs of intestinal distress when CT-scan is performed, en- 
doscopic detorsion and decompression can be performed as a first-line emergency. This has the advantage of allowing delayed radical surgery to be performed under better conditions [1] [3]. However, as this endoscopic method is not performed in Mali, treatment of colon volvulus remains an indication for surgery from the outset.

\section{Conclusion}

Synchronous volvulus of the sigmoid colon and transverse colon is a very rare medical and surgical emergency. The clinical signs are not specific and the discovery is often intraoperative. It is necessary to know how to evoke the diagnosis in a case of sigmoid colon volvulus, to avoid inadequate management with dramatic consequences.

\section{Consent}

We confirm that Consent has been obtained.

\section{Conflicts of Interest}

The authors declare no conflicts of interest regarding the publication of this paper.

\section{References}

[1] Motsumi, M.J. and Tlhomelang, O. (2018) Synchronous Volvulus of the Sigmoid and Transverse Colon in a 26-Year-Old Male. Journal of Surgical Case Reports, 11 1-3. https://doi.org/10.1093/jscr/rjy295

[2] Hoseini, A., Samani, R.E., Parsamoin, H. and Jafari, H. (2014) Synchronic Volvulus of Sigmoid and Transverse Colon: A Rare Case of Large Bowel Obstruction. Annals of Colorectal Research, 2, e16520. https://doi.org/10.17795/acr-16520

[3] Samlali, A., Boussaidane, S., Hamri, A., Narjis, Y. and Benomar, R.B. (2021) Volvulus synchrone du côlon transverse et sigmoïde: Un cas rare d'occlusion du gros intestin. The Pan African Medical Journal, 38, 1-5. https://doi.org/10.11604/pamj.2021.38.8.27407

[4] Eldirdiri, S., Musa, I.H., Adamb, H.Y., Sulimanb, A.G., Ata Elmananb, M.M., Eldirdiri, S., et al. (2019) Transverse Colonic Volvulus after Resection of Sigmoid Volvulus: Presentation of a Case Report. International Journal of Surgery Case Reports, 60, 257-260. https://doi.org/10.1016/j.ijscr.2019.06.008

[5] Lianos, G., Ignatiadou, E., Lianou, E., Anastasiadi, Z. and Fatouros, M. (2012) Simultaneous Volvulus of the Transverse and Sigmoid Colon. Case Report. Il Giornale di chirurgia, 33, 324-326.

[6] Ndong, A., Diao, M.L., Tendeng, J.N., Diallo, A.C., Ma Nyemb, P.M. and Konaté, I. (2020) Synchronous Sigmoid and Transverse Volvulus: A Case Report and Qualitative Systematic Review. International Journal of Surgery Case Reports, 75, 297-301. https://doi.org/10.1016/j.ijscr.2020.09.027

[7] Katsanos, K., Ignatiadou, E., Markouizos, G., Doukas, M., Siafakas, M., Fatouros, M., et al. (2009) Non-Toxic Megacolon Due to Transverse and Sigmoid Colon Volvulus in a Patient with Ulcerative Colitis. Journal of Crohn's and Colitis, 3, 38-41. https://doi.org/10.1016/j.crohns.2008.09.002

[8] McBrearty, A., Harris, A. and Gidwani, A. (2011) Transversesigmoid Colon Knot: A 
Rare Cause of Bowel Obstruction. Ulster Medical Journal, 80, 107-108.

[9] Togo, A., Kanté, L., Diakité, I., Dembélé, B.T., Traoré, A., Diarra, A., Kelly, B., Kanté, A., Tounkara, I., Bengaly, B., Karembé, B. and Diallo, G. (2014) Volvulus du sigmoïde (VS) sans nécrose: Colectomie idéale ou résection anastomose en 2 temps? Journal Africain d' Hépato-Gastroentérologie, 8, 61-65.

https://doi.org/10.1007/s12157-014-0517-4 